\title{
Adenylyl Cyclase (AC) Mediates the Antidepressant-Like Effects of Tropisetron on a Mouse Model of Maternal Separation Stress
}

\author{
Ali Hosseinzadeh, ${ }^{1}$ Shakiba Nasiri Boroujeni (D), ${ }^{1}$ Elham Saghaei ${ }^{D},{ }^{1}$ Zahra Loriooini ${ }^{1 D}{ }^{1}$ \\ Saeid Habibian Dehkordi, ${ }^{2}$ Shima Balali-Dehkordi, ${ }^{1}$ Mohammad Rahimi-Madiseh ${ }^{10},{ }^{1}$ \\ and Hossein Amini-Khoei $\mathbb{D D}^{1}$ \\ ${ }^{1}$ Medical Plants Research Center, Basic Health Sciences Institute, Shahrekord University of Medical Sciences, Shahrekord, Iran \\ ${ }^{2}$ Department of Basic Sciences, Veterinary Faculty, Shahrekord University, Shahrekord, Iran \\ Correspondence should be addressed to Hossein Amini-Khoei; aminikhoyi@gmail.com
}

Received 20 February 2021; Revised 10 April 2021; Accepted 16 April 2021; Published 22 April 2021

Academic Editor: Janusz K. Rybakowski

Copyright (c) 2021 Ali Hosseinzadeh et al. This is an open access article distributed under the Creative Commons Attribution License, which permits unrestricted use, distribution, and reproduction in any medium, provided the original work is properly cited.

\begin{abstract}
The adenylyl cyclase (AC) pathway is involved in the pathophysiology of depression. Finding new antidepressants with high medicinal properties and low side effects is warranted. Therefore, this study was designed to determine the antidepressant-like effect of tropisetron on a maternal separation (MS) model in mice, considering the possible role of AC. NMRI male mice were divided into eleven groups. The control group was treated with saline and MS groups were treated with saline, tropisetron (a 5HT3 receptor antagonist) at doses of 1,3 , and $5 \mathrm{mg} / \mathrm{kg}$; forskolin (an activator of AC) at doses of 5,10, and $25 \mathrm{mg} / \mathrm{kg}$; a subeffective dose of forskolin with a subeffective dose of tropisetron; and an effective dose of tropisetron plus an effective dose of NB001 (3 mg/kg) (an AC inhibitor). After treatment, animals were subjected to behavioral tests including the forced swimming test (FST), splash test, and open field test (OFT). We showed that MS caused depressive-like behaviors determined as an increase in the immobility time in the forced swimming test (FST) and decreased grooming time in the splash test. Our results showed that administration of tropisetron, as well as forskolin, mitigated the depressive-like behaviors in MS mice. We found that coadministration of a subeffective dose of tropisetron plus a subeffective dose of forskolin potentiated the antidepressantlike effect of tropisetron. However, coadministration of an effective dose of NB001 with an effective dose of tropisetron did not significantly affect the antidepressant-like effect of tropisetron. We concluded that the antidepressant-like effects of tropisetron on MS mice are partially mediated through the adenylyl cyclase pathway.
\end{abstract}

\section{Introduction}

Depression is one of the most common psychological disorders [1]. More than $15 \%$ of people experience at least one period of depression in developed countries in their lifetime $[2,3]$. The emotional relationship between the mother and the infant in childhood has been shown to play an important role in neurodevelopment and behavioral responses in adulthood [4]. Maternal care at early life is associated with improved biological behavior and physiological development and subsequently increases social adjustment [5]. Experiencing unfortunate events like maternal separation (MS) in the early stages of life has a negative effect on behavior and brain development and potentially acts as a risk factor for psychological disorders such as depression in adulthood [6-8].
Monoamine serotonin or 5-hydroxytryptamine (5-HT) is an important neurotransmitter in the pathophysiology of depressive disorder and is also involved in the mechanisms of action of commonly used antidepressants [9]. Studies in both animal and clinical models have shown that depression is clearly associated with a decrease in the level of serotonin in the central nervous system (CNS) [10-13]. 5-HT regulates various biological functions such as mood, sleep, appetite, daily rhythms, and energy balance [14]. Evidence suggests that the 5-HT3 receptor, as ion channel ligands, is involved in brain development and maturation. This receptor is widely distributed in the CNS and plays an important role in regulating various processes and different brain functions. Previous studies have shown that the 5-HT3 receptor antagonists, including tropisetron and ondansetron, possessed antidepressant-like 
properties in animal models of depression $[15,16]$. However, the exact mechanisms that are involved in the antidepressantlike effect of tropisetron have not been fully determined.

Adenylyl cyclase (AC) is an enzyme that converts ATP to cAMP $[17,18]$. A number of studies have shown that AC is involved in the pathophysiology of depression $[19,20]$. Platelet AC activity has been shown to act as a biological marker for the evaluation of the depressive state [21-24]. This is based on the fact that people with a history of depression have lower levels of platelet AC activity [25]. Forskolin is one of the AC agonists that increase the formation of intracellular CAMP. Previous studies have showed that forskolin can be considered as an agent with potential antidepressant effect $[6,8,26,27]$.

Considering that tropisetron exerted an antidepressantlike effect and also involvement of AC in the pathophysiology of depression, the present study is designed to evaluate the possible involvement of AC in the antidepressant-like effect of tropisetron on a mouse model of MS-induced depression.

\section{Material and Methods}

2.1. Maternal Separation (MS) Paradigm. Pregnant NMRI mice (Pasteur Institute, Tehran, Iran) were used. The animals were kept under standard laboratory conditions (12-hour light/dark cycle, $22 \pm 1^{\circ} \mathrm{C}$ and free access to water and food). To perform the MS paradigm as described by Lorigooini et al., the birthday was considered as postnatal day 0 (PND0). Pups from PND2 to PND14 were then separated from their mothers for 3 hours a day and then returned to their mother's cage. At the end of PND14, the mice were returned to their mother's cage and remained there until PND21 [28]. On day 21, male mice were divided into ten groups $(n=8)$ until the day of the experiment (PND60). All procedures were carried out in accordance with the regulations of the university and the Guide for the Care and Use of Laboratory Animals of National Institutes of Health (ethics code: IR.SKUMS.REC.1397.120) and Guide for the Care and Use of Laboratory Animals (8th edition, National Academies Press). Full efforts were made to reduce the use of animals and to advance their welfare.

2.2. Experimental Groups. Mice were divided into 11 groups $(n=6)$ as follows: group $1-$ control mice which received normal saline; group 2-MS mice which received normal saline; groups 3-5-MS mice which received tropisetron at doses of 1,3 , and $5 \mathrm{mg} / \mathrm{kg}$, respectively; groups 6-8-MS mice which received forskolin (an activator of $\mathrm{AC}$ ) at doses of 5, 10, and $25 \mathrm{mg} / \mathrm{kg}$, respectively; group 9-MS mice cotreated with tropisetron at a dose of $1 \mathrm{mg} / \mathrm{kg}$ (subeffective dose) plus a subeffective dose of forskolin ( $5 \mathrm{mg} / \mathrm{kg}$ ), simultaneously; group $10-\mathrm{MS}$ mice cotreated with an effective dose of tropisetron $(5 \mathrm{mg} / \mathrm{kg})$ plus an effective dose of AC inhibitor (NB001, $3 \mathrm{mg} / \mathrm{kg}$ ), simultaneously; and group $11-\mathrm{MS}$ mice which received fluoxetine at a dose of $5 \mathrm{mg} / \mathrm{kg}$. The dose and time of drug administration were chosen based on previous studies and our pilot study [29-33]. Drugs were dissolved in physiological saline and injected as a single dose via an intraperitoneal (i.p.) route with a volume of $5 \mathrm{ml} / \mathrm{kg}$ body weight.
Agents were injected one hour before the behavioral tests. 132 mice were used in this study. Different sets of mice were used for behavioral tests. One set for the OFT and FST and another set for the splash test.

2.3. Open Field Test (OFT). The OFT was performed to evaluate the locomotion following treatments. The OFT was done immediately before the FST to consider ambulatory behavior as well as to confirm that adjustments which occur in motor activity did not affect the immobility time in the FST. The OFT device is a white Plexiglas with dimensions of $30 \times 50 \times 50 \mathrm{~cm}$. Each mouse was gently placed at the center of the device. Its movements were recorded for 5 minutes by the camera and evaluated by EthoVision version 8 software. In the OFT, the horizontal (number of crossing by 4 foots from each square) activity was measured. The apparatus was cleaned with $70 \%$ ethanol after the experiment with each mouse $[28,34]$.

2.4. Forced Swimming Test (FST). In this test, the immobility time of mice, along with frustrating behavior as a reflection of depressive-like behavior, was recorded. To do this, a glass container $(25 \times 12 \times 15 \mathrm{~cm})$ was filled with $25^{\circ} \mathrm{C}$ water and the mouse was placed gently in the water from a height of $20 \mathrm{~cm}$. Disruption of mouse movements was considered immobility. The test time was 6 minutes; the first 2 minutes was considered to match the animal with the current conditions, and the immobility time was measured for the next 4 minutes [35].

2.5. Splash Test. The splash test was used to examine personal care and motivational problems in mice. To do this, a $10 \%$ sucrose solution was sprayed on the dorsal coat of the mouse and its behavior was filmed for 5 minutes. In this test, selfcleaning activities including nose/face cleaning, head washing, and body grooming were measured [36].

2.6. Data Analysis. Data were analysed using Prism software, and then, the results were displayed as mean \pm S.E.M. Data were analysed using one-way ANOVA and Tukey's post hoc test. $P<0.05$ was considered statistically significant.

\section{Results}

3.1. Locomotor Activity in the OFT. One-way ANOVA analysis showed that there are significant differences amongst experimental groups in the case of horizontal activity ( $F$ $(10,55)=16.46, P<0.001)$. Findings showed that the MS group's horizontal activities were significantly lower than those of the control group $(P<0.001$, Figure 1$)$. The horizontal activities in the MS mice who received forskolin at doses of 5 and $25 \mathrm{mg} / \mathrm{kg}$ were significantly higher than those in the saline-treated MS group $(P>0.05$ and $P<0.001$, respectively). We observed that the horizontal activities in MS mice that received coadministration of tropisetron $(5 \mathrm{mg} / \mathrm{kg})$ plus NB001 were significantly increased compared to those in the group that received tropisetron at the dose of $5 \mathrm{mg} / \mathrm{kg}$ alone $(P<0.01)$. We did not observe significant alterations in cases of horizontal activities in groups that received 


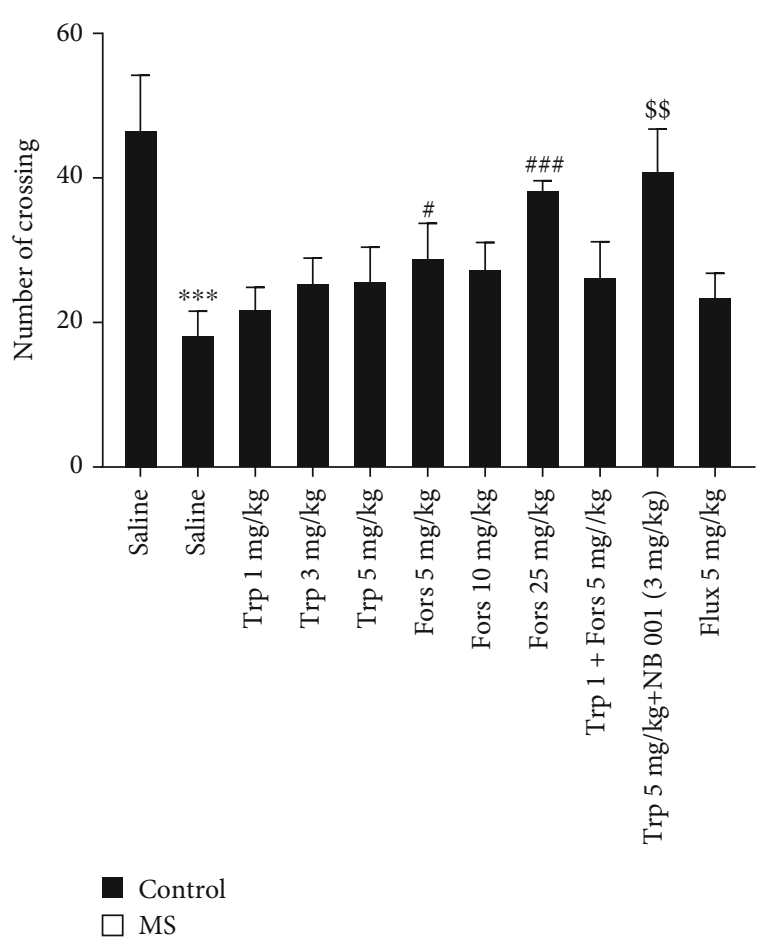

Figure 1: Horizontal activity in the OFT. Values are presented as the mean \pm S.E.M. from 6 animals and were analysed using oneway ANOVA followed by Tukey's post test. Drugs were dissolved in physiological saline and injected as a single dose via intraperitoneal (i.p.) route with a volume of $5 \mathrm{ml} / \mathrm{kg}$ body weight one hour before the test. ${ }^{* * *} P<0.001$ compared with the salinetreated control group, ${ }^{\#} P<0.05$ and ${ }^{\# \# \# ~} P<0.001$ compared with the saline-treated MS group, and ${ }^{\$} P<0.01$ compared with the tropisetron- $(5 \mathrm{mg} / \mathrm{kg})$ received MS group. MS: maternal separation; Trp: tropisetron; Flux: fluoxetine; Fors: forskolin.

tropisetron at different doses as well as fluoxetine in comparison with those in saline-treated control mice $(P>0.05)$.

3.2. Immobility Time in the FST. One-way ANOVA analysis showed that there are significant differences amongst experimental groups in cases of immobility time in the FST $(F$ $(10,55)=56.18, P<0.001)$. As shown in Figure 2 , the duration of immobility in the FST in the MS group was significantly longer than that in the control group $(P<0.001)$. The immobility time in the MS groups that received tropisetron at the doses of 3 and $5 \mathrm{mg} / \mathrm{kg}$ was significantly reduced compared to that in the saline-treated MS mice $(P<0.001)$. The forskolin-received MS mice (doses of 10 and $25 \mathrm{mg} / \mathrm{kg}$ ) have lower immobility time compared to the saline-treated MS group $(P<0.001)$. Coadministration of subeffective doses of tropisetron $(1 \mathrm{mg} / \mathrm{kg})$ with a subeffective dose of forskolin $(5 \mathrm{mg} / \mathrm{kg})$ significantly reduced the immobilization time compared to that of the MS group that received the subeffective dose of tropisetron alone $(P<0.001)$. In addition, coadministration of effective doses of tropisetron $(5 \mathrm{mg} / \mathrm{kg})$ with an effective dose of NB001 $(3 \mathrm{mg} / \mathrm{kg})$ did not significantly reduce the immobility time compared to that of the MS group that received the effective dose of tropisetron alone $(P>0.05)$. Results demonstrated that fluoxetine

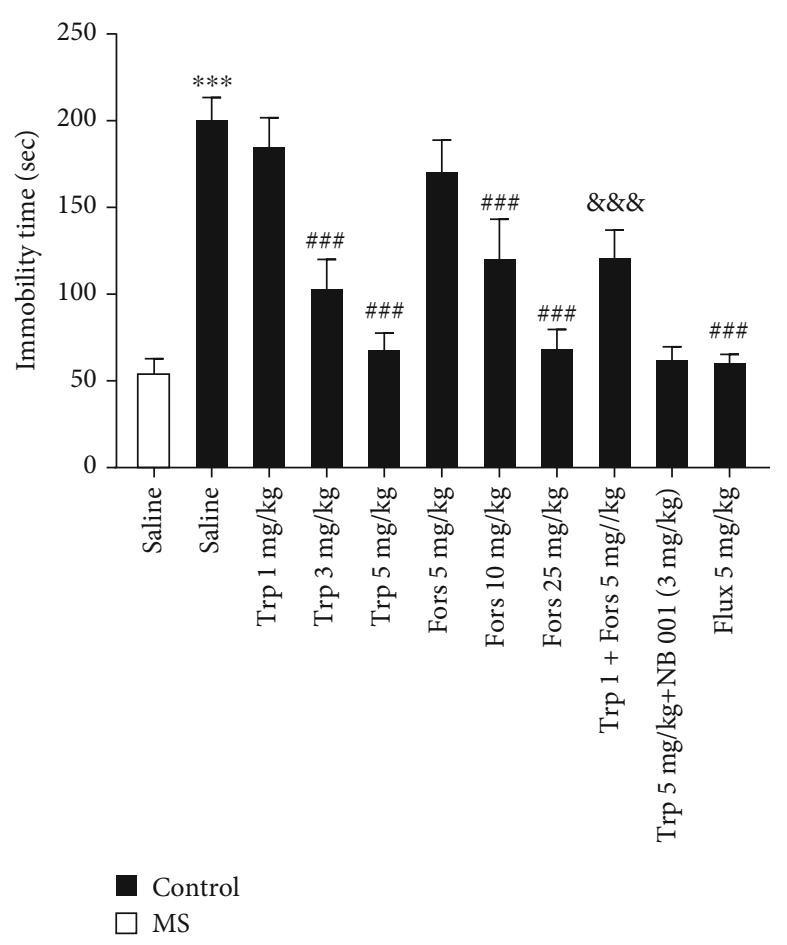

FIgURE 2: Immobility time in the FST. Values are presented as the mean \pm S.E.M. from 6 animals and were analysed using one-way ANOVA followed by Tukey's post test. Drugs were dissolved in physiological saline and injected as a single dose via intraperitoneal (i.p.) route with a volume of $5 \mathrm{ml} / \mathrm{kg}$ body weight one hour before the test. ${ }^{* * *} P<0.001$ compared with the saline-treated control group, \#\#\# $P<0.001$ compared with the saline-treated MS group, and $\& \& \& P<0.001$ compared with the tropisetron- $(1 \mathrm{mg} / \mathrm{kg})$ received MS group. MS: maternal separation; Trp: tropisetron; Flux: fluoxetine; Fors: forskolin.

$(5 \mathrm{mg} / \mathrm{kg})$ significantly decreased the immobility time in comparison with that of saline-treated MS mice $(P<0.001)$.

3.3. Grooming Activity Time in the Splash Test. One-way ANOVA analysis determined that the grooming activity time is significantly different amongst experimental groups ( $F$ $(10,55)=36.24, P<0.001)$. According to the results (Figure 3), the grooming activity time in the splash test in the MS group was significantly lower than that in the control group $(P<0.001)$. Administration of tropisetron at doses of 3 and $5 \mathrm{mg} / \mathrm{kg}$ significantly increased the grooming activity time in the MS mice compared to the saline-treated MS mice $(P<0.01$ and $P<0.001$, respectively). Our results showed that the grooming activity time in the MS groups that received forskolin at doses of 10 and $25 \mathrm{mg} / \mathrm{kg}$ significantly increased compared to those in the saline-received MS counterparts $(P<0.001)$. Simultaneous administration of subeffective doses of tropisetron $(1 \mathrm{mg} / \mathrm{kg})$ plus a subeffective dose of forskolin $(5 \mathrm{mg} / \mathrm{kg})$ significantly increased the grooming activity time compared to that of the MS group that received a subeffective dose of tropisetron alone $(P<0.001)$. Furthermore, coadministration of effective doses of tropisetron $(5 \mathrm{mg} / \mathrm{kg})$ plus an effective dose of NB001 $(3 \mathrm{mg} / \mathrm{kg})$ did not significantly increase the grooming activity 


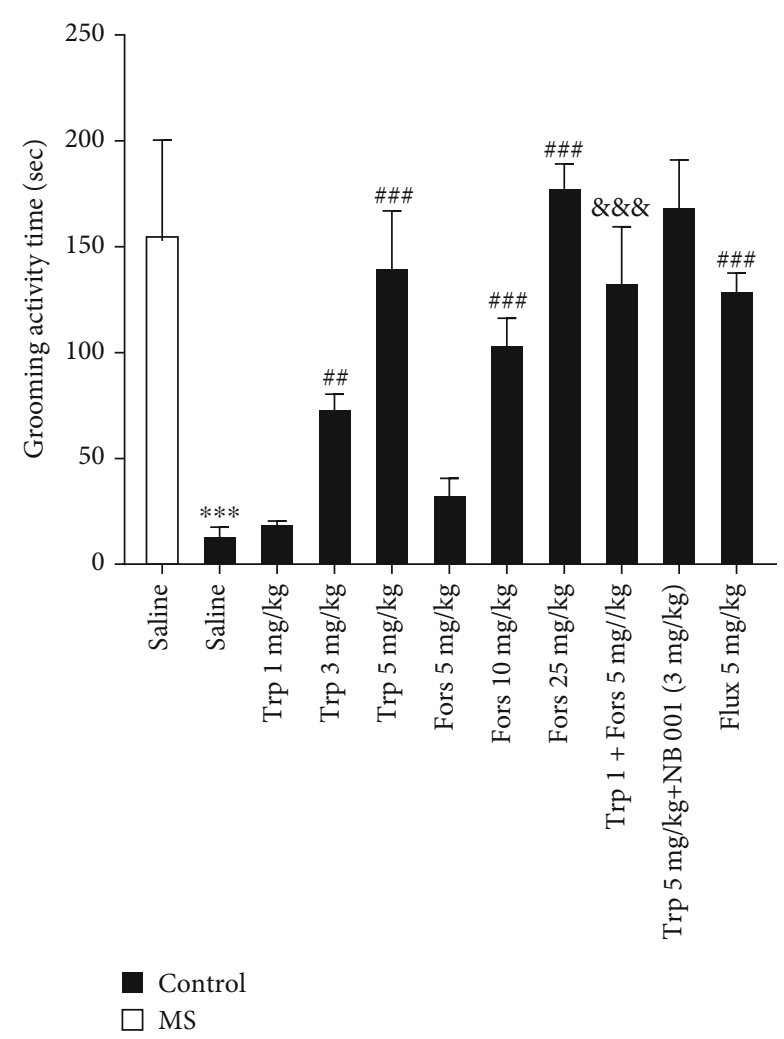

FIgURE 3: Grooming activity time in the splash test. Values are presented as the mean \pm S.E.M. from 6 animals and were analysed using one-way ANOVA followed by Tukey's post test. Drugs were dissolved in physiological saline and injected as a single dose via intraperitoneal (i.p.) route with a volume of $5 \mathrm{ml} / \mathrm{kg}$ body weight one hour before the test. ${ }^{* * *} P<0.001$ compared with the salinetreated control group, \#\# $P<0.01$ and \#\#\# $P<0.001$ compared with the saline-treated MS group, and ${ }^{\& \& \&} P<0.001$ compared with the tropisetron- $(1 \mathrm{mg} / \mathrm{kg})$ received MS group. MS: maternal separation; Trp: tropisetron; Flux: fluoxetine; Fors: forskolin.

time compared to that of the MS group that received the effective dose of tropisetron alone $(P>0.05)$. Results showed that fluoxetine $(5 \mathrm{mg} / \mathrm{kg})$ significantly increased the grooming activity time in comparison with that of saline-treated MS mice $(P<0.001)$.

\section{Discussion}

Results of the present study showed that MS provoked depressive-like behaviors in the FST and splash test as the increase in the immobility time and the decrease in the grooming activity time, respectively. We showed that tropisetron mitigated the negative effect of MS on mouse behaviors. Findings showed that forskolin (an activator of AC) potentiated the antidepressant-like effect of the subeffective dose of tropisetron.

Previous studies have shown that MS increases the risk of depressive-like behaviors in adulthood [37]. It has been determined that MS changes the neurotransmitter systems, such as the serotonergic system in the brain, and creates long-term and enduring negative effects on brain development and behavior in the adulthood [38]. Disruption in the serotonergic system is strongly involved in the pathophysiology of depression [39]. Ample evidence showed that MS increased the duration of immobility in the FST and reduced the grooming activity time in the splash test [37]. Our findings are in agreement with previous studies and determined that the MS causes depressive-like behaviors in the FST and splash test, as immobility time in MS mice increased in the FST test and the self-care and self-cleaning times significantly decreased in the splash test. In addition, we performed the OFT to approve that locomotor activity subsequent of treatments does not affect the FST results and the immobility of animals in the FST is not associated with their hypolocomotion [40]. The OFT was performed directly before the FST to measure ambulatory behavior and approve that inconsistencies which happen in motor activity did not affect the immobility time in the FST.

In 2006, Bravo and Maswood showed that treatment with a single dose of tropisetron reduced the rate of immobility in the FST [35]. In 2016, Haj-Mirzaian et al. conducted a study examining the contribution of nitric oxide and guanosine monophosphate cycles to the antidepressant-like effect of tropisetron and ondansetron on mice. They found that nitric oxide mediated the antidepressant-like effect of 5-HT3 antagonists in the FST and tail suspension test [41]. In 2016, Kordjazy et al. conducted a study and determined that NMDA receptors are involved in the antidepressant-like effect of 5-HT3 antagonists [15]. In 2016, Haj-Mirzaian et al. demonstrated that tropisetron significantly reduced the immobility in the FST and increased grooming activity in the splash test in mice [42]. The results of the mentioned studies confirm the results obtained from our study. In which, tropisetron exerted antidepressant effects in the FST, OFT, and splash test. However, the exact and full underlying mechanisms that are involved in the antidepressant-like effect of tropisetron have not been understood. Thus, in this study, we evaluated the possible involvement of the adenylyl cyclase pathway in this beneficial effect of tropisetron.

In 1996, Menninger and Tabakoff conducted a study to evaluate the effect of forskolin as a stimulant of platelet adenylyl cyclase in people with depression. This study indicates that the difference in the activity of platelet adenylyl cyclase is related to the difference in people with a history of depression [43]. Lowther et al., in 1996, showed that the AC receptor had a lower level of stimulation in depressed patients [44]. In 2005, Hines and Tabakoff conducted a study to evaluate the activity of platelet AC as a marker in depression. Their results showed that people with depression have lower levels of platelet AC activity [22]. The results of these studies confirm the effective role of $\mathrm{AC}$ in the development of depressive symptoms. The results of the present study are in line with the results of the above studies. We showed that stimulation of the AC receptor using forskolin potentiated the antidepressant-like effect of tropisetron. Surprisingly, we observed that inhibition of AC using NB001 did not attenuate the antidepressant-like effect of tropisetron. Further studies are needed to identify the reason for this response.

Bard et al. showed that stimulation of the 5-HT receptor in a dose-dependent manner causes transient accumulation of cAMP in cells which is similar to the activity of AC [45]. 
To date, no studies have investigated the role of the AC receptor in the antidepressant effect of tropisetron. The results of the present study showed that the subeffective dose of tropisetron in combination with the subeffective dose of the activator of AC (forskolin) enhanced the antidepressant-like effect of tropisetron in the FST and splash test. However, coadministration of tropisetron with the AC inhibitor (NB001) did not mitigate the beneficial effect of tropisetron. Our findings indicate that the $\mathrm{AC}$ receptor is involved in the antidepressant-like effect of tropisetron. It seems necessary to conduct more detailed studies in this field to clarify more this involvement.

\section{Conclusion}

The results of the present study showed that the administration of tropisetron in a dose-dependent manner exerted the antidepressant-like effect on MS mice. We found that the adenylyl cyclase receptor partially, at least, mediated the antidepressant-like effect of tropisetron.

\section{Data Availability}

The original data used to support the findings of this study are included within the article.

\section{Additional Points}

Limitations of the Study. The limitation of the study included a single and relatively short treatment period.

\section{Conflicts of Interest}

The authors have no conflicts of interest to declare regarding the study described in this article and preparation of the article.

\section{Acknowledgments}

This study was supported by a research grant (2830) from Shahrekord University of Medical Sciences, Shahrekord, Iran. The authors are thankful for Dr. Mehrdad Shahrani Korani and Mrs. Elham Bijad for their contributions to this study.

\section{References}

[1] M. Anjomshoa, S. N. Boroujeni, S. Ghasemi et al., "Rutin via increase in the CA3 diameter of the hippocampus exerted antidepressant-like effect in mouse model of maternal separation stress: possible involvement of NMDA receptors," Behavioural Neurology, vol. 2020, Article ID 4813616, 9 pages, 2020.

[2] R. C. Kessler and E. J. Bromet, "The epidemiology of depression across cultures," Annual review of public health, vol. 34, no. 1, pp. 119-138, 2013.

[3] M. E. Kruijshaar, J. Barendregt, T. Vos, R. De Graaf, J. Spijker, and G. Andrews, "Lifetime prevalence estimates of major depression: an indirect estimation method and a quantification of recall bias," European journal of epidemiology, vol. 20, no. 1, pp. 103-111, 2005.

[4] R. A. Millstein and A. Holmes, "Effects of repeated maternal separation on anxiety- and depression-related phenotypes in different mouse strains," Neuroscience \& Biobehavioral Reviews, vol. 31, no. 1, pp. 3-17, 2007.

[5] M. Arabi, S. H. Nasab, Z. Lorigooini et al., "Auraptene exerts protective effects on maternal separation stress-induced changes in behavior, hippocampus, heart and serum of mice," International Immunopharmacology, vol. 93, article 107436, 2021.

[6] P. Pechtel and D. A. Pizzagalli, "Effects of early life stress on cognitive and affective function: an integrated review of human literature," Psychopharmacology, vol. 214, no. 1, pp. 55-70, 2011.

[7] N. R. Nugent, A. R. Tyrka, L. L. Carpenter, and L. H. Price, "Gene-environment interactions: early life stress and risk for depressive and anxiety disorders," Psychopharmacology, vol. 214, no. 1, pp. 175-196, 2011.

[8] S. J. Lupien, B. S. McEwen, M. R. Gunnar, and C. Heim, "Effects of stress throughout the lifespan on the brain, behaviour and cognition," Nature Reviews Neuroscience, vol. 10, no. 6, pp. 434-445, 2009.

[9] C. A. Stockmeier, "Involvement of serotonin in depression: evidence from postmortem and imaging studies of serotonin receptors and the serotonin transporter," Journal of Psychiatric Research, vol. 37, no. 5, pp. 357-373, 2003.

[10] A. J. Eisch and D. Petrik, "Depression and hippocampal neurogenesis: a road to remission?," Science, vol. 338, no. 6103, pp. 72-75, 2012.

[11] J. L. Lukkes, G. H. Engelman, N. S. Zelin, M. W. Hale, and C. A. Lowry, "Post-weaning social isolation of female rats, anxiety-related behavior, and serotonergic systems," Brain Research, vol. 1443, pp. 1-17, 2012.

[12] A. C. Bledsoe, K. M. Oliver, J. L. Scholl, and G. L. Forster, "Anxiety states induced by post-weaning social isolation are mediated by CRF receptors in the dorsal raphe nucleus," Brain research bulletin, vol. 85, no. 3-4, pp. 117-122, 2011.

[13] J. T. Yorgason, R. A. Espana, J. K. Konstantopoulos, J. L. Weiner, and S. R. Jones, "Enduring increases in anxietylike behavior and rapid nucleus accumbens dopamine signaling in socially isolated rats," European Journal of Neuroscience, vol. 37, no. 6, pp. 1022-1031, 2013.

[14] N. L. Baganz and R. D. Blakely, "A dialogue between the immune system and brain, spoken in the language of serotonin," ACS chemical neuroscience, vol. 4, no. 1, pp. 48-63, 2013.

[15] N. Kordjazy, A. Haj-Mirzaian, S. Amiri, S. Ostadhadi, H. Amini-Khoei, and A. R. Dehpour, "Involvement of Nmethyl-d-aspartate receptors in the antidepressant-like effect of 5-hydroxytryptamine 3 antagonists in mouse forced swimming test and tail suspension test," Pharmacology Biochemistry and Behavior, vol. 141, pp. 1-9, 2016.

[16] L. Nguyen, J.-M. Rigo, V. Rocher et al., "Neurotransmitters as early signals for central nervous system development," Cell and tissue research, vol. 305, no. 2, pp. 187-202, 2001.

[17] S. Pierre, T. Eschenhagen, G. Geisslinger, and K. Scholich, "Capturing adenylyl cyclases as potential drug targets," Nature reviews Drug discovery, vol. 8, no. 4, pp. 321-335, 2009.

[18] N. Wray, M. Pergadia, D. Blackwood et al., "Genome-wide association study of major depressive disorder: new results, meta-analysis, and lessons learned," Molecular Psychiatry, vol. 17, no. 1, pp. 36-48, 2012.

[19] B. Tabakoff and P. L. Hoffman, "Transducing emotionality: the role of adenylyl cyclases," Biological Psychiatry, vol. 71, no. 7, pp. 572-573, 2012. 
[20] H. Metzger and E. Lindner, "The positive inotropic-acting forskolin, a potent adenylate cyclase activator," Arzneimittel-Forschung, vol. 31, no. 8, pp. 1248-1250, 1981.

[21] P. L. Hoffman, J. Glanz, and B. Tabakoff, "Platelet adenylyl cyclase activity as a state or trait marker in alcohol dependence: results of the WHO/ISBRA study on state and trait markers of alcohol use and dependence," Alcoholism: Clinical and Experimental Research, vol. 26, no. 7, pp. 1078-1087, 2002.

[22] L. M. Hines, B. Tabakoff, and WHO/ISBRA Study on State and Trait Markers of Alcohol Use and Dependence Investigators, "Platelet adenylyl cyclase activity: a biological marker for major depression and recent drug use," Biological Psychiatry, vol. 58, no. 12, pp. 955-962, 2005.

[23] P. L. Katsel, T. M. Tagliente, T. E. Schwarz, B. D. CraddockRoyal, N. D. Patel, and S. Maayani, "Molecular and biochemical evidence for the presence of type III adenylyl cyclase in human platelets," Platelets, vol. 14, no. 1, pp. 21-33, 2003.

[24] M. Montminy, "Transcriptional regulation by cyclic AMP," Annual Review of Biochemistry, vol. 66, no. 1, pp. 807-822, 1997.

[25] W. J. Tang and J. H. Hurley, "Catalytic mechanism and regulation of mammalian adenylyl cyclases," Molecular Pharmacology, vol. 54, no. 2, pp. 231-240, 1998.

[26] K. B. Seamon, W. Padgett, and J. W. Daly, "Forskolin: unique diterpene activator of adenylate cyclase in membranes and in intact cells," Proceedings of the National Academy of Sciences, vol. 78, no. 6, pp. 3363-3367, 1981.

[27] Y. Bersudsky, M. Kotler, M. Shifrin, and R. Belmaker, “A preliminary study of possible psychoactive effects of intravenous forskolin in depressed and schizophrenic patients," Journal of Neural Transmission, vol. 103, no. 12, pp. 1463-1467, 1996.

[28] Z. Lorigooini, S. N. Boroujeni, M. Sayyadi-Shahraki, M. Rahimi-Madiseh, E. Bijad, and H. Amini-Khoei, "Limonene through attenuation of neuroinflammation and nitrite level exerts antidepressant-like effect on mouse model of maternal separation stress," Behavioural Neurology, vol. 2021, Article ID 8817309, 8 pages, 2021.

[29] A. Hemat-Far, A. Shahsavari, and S. R. Mousavi, "Effects of selected aerobic exercises on the depression and concentrations of plasma serotonin in the depressed female students aged 18 to 25," Journal of Applied Research, vol. 12, no. 1, 2012.

[30] D. G. Machado, M. P. Kaster, R. W. Binfaré et al., “Antidepressant-like effect of the extract from leaves of_Schinus molle_L _._ in mice: Evidence for the involvement of the monoaminergic system," Progress in Neuro-Psychopharmacology and Biological Psychiatry, vol. 31, no. 2, pp. 421-428, 2007.

[31] I. Lucki, "The forced swimming test as a model for core and component behavioral effects of antidepressant drugs," Behavioural Pharmacology, vol. 8, no. 6, pp. 523-532, 1997.

[32] M.-M. Zhang, S.-B. Liu, T. Chen et al., "Effects of NB001 and gabapentin on irritable bowel syndrome-induced behavioral anxiety and spontaneous pain," Molecular brain, vol. 7, no. 1, p. $47,2014$.

[33] A. S. B. Ershadi, H. Amini-Khoei, M.-J. Hosseini, and A. R. Dehpour, "SAHA improves depressive symptoms, cognitive impairment and oxidative stress: rise of a new antidepressant class," Neurochemical Research, vol. 46, no. 5, pp. 1252-1263, 2021.

[34] H. Takeda, M. Tsuji, M. Inazu, T. Egashira, and T. Matsumiya, "Rosmarinic acid and caffeic acid produce antidepressive-like effect in the forced swimming test in mice," European journal of pharmacology, vol. 449, no. 3, pp. 261-267, 2002.

[35] G. Bravo and S. Maswood, "Acute treatment with 5-HT3 receptor antagonist, tropisetron, reduces immobility in intact female rats exposed to the forced swim test," Pharmacology Biochemistry and Behavior, vol. 85, no. 2, pp. 362-368, 2006.

[36] J́. A. Navarro-Gonzálvez, C. García-Benayas, and J. Arenas, "Semiautomated measurement of nitrate in biological fluids," Clinical chemistry, vol. 44, no. 3, pp. 679-681, 1998.

[37] A. Lesse, K. Rether, N. Gröger, K. Braun, and J. Bock, “Chronic postnatal stress induces depressive-like behavior in male mice and programs second-hit stress-induced gene expression patterns of OxtR and AvpRla in adulthood," Molecular Neurobiology, vol. 54, no. 6, pp. 4813-4819, 2017.

[38] W. Daniels, C. Pietersen, M. Carstens, and D. Stein, "Maternal separation in rats leads to anxiety-like behavior and a blunted ACTH response and altered neurotransmitter levels in response to a subsequent stressor," Metabolic Brain Disease, vol. 19, no. 1/2, pp. 3-14, 2004.

[39] H. Joffe and L. S. Cohen, "Estrogen, serotonin, and mood disturbance: where is the therapeutic bridge?," Biological Psychiatry, vol. 44, no. 9, pp. 798-811, 1998.

[40] B. S. F. Mello, A. J. M. Chaves Filho, C. S. Custódio et al., "Sex influences in behavior and brain inflammatory and oxidative alterations in mice submitted to lipopolysaccharide-induced inflammatory model of depression," Journal of Neuroimmunology, vol. 320, pp. 133-142, 2018.

[41] A. Haj-Mirzaian, N. Kordjazy, S. Amiri et al., "Involvement of nitric oxide-cyclic guanosine monophosphate pathway in the antidepressant-like effect of tropisetron and ondansetron in mice forced swimming test and tail suspension test," European Journal of Pharmacology, vol. 780, pp. 71-81, 2016.

[42] A. Haj-Mirzaian, S. Amiri, H. Amini-Khoei et al., "Attenuation of oxidative and nitrosative stress in cortical area associates with antidepressant-like effects of tropisetron in male mice following social isolation stress," Brain Research Bulletin, vol. 124, pp. 150-163, 2016.

[43] J. A. Menninger and B. Tabakoff, "Forskolin-stimulated platelet adenylyl cyclase activity is lower in persons with major depression," Biological Psychiatry, vol. 42, no. 1, pp. 30-38, 1997.

[44] S. Lowther, M. Crompton, C. Katona, and R. Horton, "GTP gamma $\mathrm{S}$ and forskolin-stimulated adenylyl cyclase activity in post-mortem brain from depressed suicides and controls," Molecular Psychiatry, vol. 1, no. 6, pp. 470-477, 1996.

[45] J. A. Bard, J. Zgombick, N. Adham, P. Vaysse, T. A. Branchek, and R. L. Weinshank, "Cloning of a novel human serotonin receptor (5-HT7) positively linked to adenylate cyclase.," Journal of Biological Chemistry, vol. 268, no. 31, pp. 23422-23426, 1993. 